\title{
Analysis of Open Access Scholarly Journals in Media \& Communication
}

\author{
Shabahat Husain* and Mohammad Nazim** \\ ${ }^{*}$ Dept. of Library \& Information Science, Aligarh Muslim University, Aligarh-202 002 \\ E-mail: shabahat12@rediffmail.com \\ ${ }^{* *}$ Faculty of Law, Banaras Hindu University, Varanasi-221 005 \\ E-mail: nazim76@gmail.com
}

\begin{abstract}
The paper gives an account of the origin and development of the Open Access Initiative and explains the concept of open access publishing. It also highlight various facets related to the open access scholarly publishing in the field of Media \& Communication on the basis of data collected from the most authoritative online directory of open access journals, i.e., Directory of Open Access Journals (DOAJ). The DOAJ covers 8492 open access journals of which 106 journals are listed under the subject heading 'Media \& Communication'. Most of the open access journals in Media \& Communication were started during late 1990s and are being published from 34 different countries on 6 continents in 13 different languages. More than $80 \%$ open access journals are being published by the not-for-profit sector such as academic institutions and universities.
\end{abstract}

Keywords: Open access journals, open access initiative, directory of open access journals, DOAJ, OAI media and communication

\section{INTRODUCTION}

Scholarly communication is often used interchangeably with the term scholarly publishing. Scholarly communication is the process of academics, scholars and researchers sharing and publishing their research findings so that they are available to the wider academic community (such as university academics) and beyond ${ }^{1}$. It includes both the dissemination and access to scholarship and research in a variety of formats and states of completion, such as published books or journal articles, research results and data sets, and drafts of papers ${ }^{2}$. Research is basically funded by public. But a publically-funded research is not allowed for the public. They have to pay for it again. Scientists disseminate the results of their research through journals. The traditional system of publishing provides an obstacle in the dissemination of research findings due to its pricing policies. Dwindling budgets, and high cost of journals are making libraries unable to purchase a good number of journals. In the present scenario, libraries are cutting the subscription of journals. Internet has changed the traditional scholarly publishing system and a new system of scholarly discourse has emerged, i.e., open access (OA) publishing system, which promises to give extreme advantages to the researchers, educational institutions, and libraries, particularly, those which have acute shortage of resources for purchasing scholarly literature. The OA movement has gained substantial popularity in developed countries and many developing countries are also taking interest in this movement. This movement is supported by different bodies such as Scholarly Publishing and Academic Resources Coalition (SPARC), Open Access Initiative (OAI), Open Society Institute (OSI), Public Library of Science (PLoS), etc. With the three important declarations, i.e., Budapest, Bethesda, and Berlin, this movement has gained momentum since $2003^{3}$.

\section{CONCEPT OF OPEN ACCESS}

By open access, one means the free and immediate availability on the public internet of those works which scholars give to the world without expectation of payment-permitting any user to read, download, copy, distribute, print, search or link to the full-text of these articles, crawl them for indexing, pass them as data to software or use them for any other lawful purpose ${ }^{4}$. The goal of the OA movement is to make scholarly literature freely available in digital form worldwide with minimal restrictions in their use. The present study is an attempt to identify the trends of 
OA publishing (particularly OA journals) in the field of media and communication. It will be helpful for media librarians as well as subject professionals to get aware of the availability of OA journals in the field of Media \& Communication.

\section{RESEARCH PROBLEM}

Despite of several directories of OA journals on internet (e.g. Directory of Open Access Journals (DOAJ)) and search engines for searching article from OA journals (e.g. Open J-Gate), the people are unaware of the availability of OA journals in different disciplines. Different movements are undertaken to promote the use of OA journals. There is a large and growing body of fully OA journals in the field of Media and Communication. The DOAJ listed 106 titles under the subject heading 'Media \& Communication' at the time of data analysis (i.e., on 15 December 2012). Several studies were conducted in different disciplines on the availability of OA journals and their impact factor, but none of the study has been undertaken to investigate OA journals in Media \& Communication. This is an area where researchers are needed to know the availability and trends of $O A$ journals publishing. The present study is useful for the librarians as well as subject concerned professionals to understand the various facets related to OA scholarly publishing in the field of Media \& Communication.

\section{LITERATURE REVIEW}

Review of related literature has always been essential for research. According to Ali ${ }^{5}$, "literature review is a comprehensive survey of the works published in a field of study, or related to a particular line of research, usually in the form of a bibliographic essay or annotated list of references in which attention is drawn to the most significant works". Literature review provides the researcher with a knowledge-base and helps in identifying the gaps in the literature.

According to Prosser ${ }^{6}$, the current model of scholarly communication failed to meet the information needs of researchers world-wide, while new technology (in particular the origin of internet) allows us to revise or reinvent scholarly communication. Anbu ${ }^{7}$ discusses the inadequacies of existing scholarly publication model, and elaborates on the advantages of OA model with particular reference to vertical portal. Ratnakar ${ }^{8}$ presents a brief overview of print journals, define OA movement, and explains the reason for existence in current scenario. According to him, OA movement also deals with promoting creation of institutional archives and usage of open source software and digitisation programme. He also highlighted the area of OA journals and open archives and present limitations of OAl movement.
Nazim \& Maya Devi ${ }^{9}$ highlighted the trends in OA publishing in India, as per their study, among the top $25 \mathrm{OA}$ publishing countries, India ranks $5^{\text {th }}$ in the list. Keisham ${ }^{10}$ describes the concept of OA and highlights some of the OA journal initiatives in India. Arunachalam ${ }^{11}$ explains the current status of scientific research and progress made in $O A$ journals, OA repositories and open courseware in India. He has also highlighted that India is feudal and hierarchical; there exists a wide variation in the level engagement with science and research and there is a wide gap between talk and action. The paper concludes that Indian Institute of Science (IISc) deposits a large proportion of the papers published by its faculty and students in the past hundreds years in its e-prints archive and the Council for Scientific and Industrial Research (CSIR) is also adopting the OA policy. Anup Kumar ${ }^{12}$ discussed how Indian OA Journals get international visibility with increased outreach through primary and secondary open access journal gateways and aggregators. This paper proposed a model of self-sustainability for OA journals as well as for OA journal publishers.

Lone, Rather \& Shah ${ }^{13}$ revealed that India is continuously contributing in OA literature as some of the premier institutions, particularly in the S\&T area which are providing open access to their research publications and revealed that India is at the $7^{\text {th }}$ position in the DOAJ and is sharing $10^{\text {th }}$ position with Sweden and Spain in Directory of Open Access Repositories (Open DOAR) in terms of number of repositories in the world. Bhat ${ }^{14}$ discussed about OA publishing in premier research institutes of India and found that the IISc publishes $8.26 \%$ of its research output in OA journals, All India Institute of Medical Sciences $19.37 \%$, Bhabha Atomic Research Centre $4.84 \%$, IIT, Delhi $3.04 \%$, and IIT, Kharagpur 3.26 $\%$ of 17,516 research articles published in 4232 journals. Thus, medical institutions are contributing more of their publications to OA journals as compared to other institutions. Sawant ${ }^{15}$ revealed that, $178 \mathrm{OA}$ journals were peer-reviewed, indexed and abstracted in various indexing and abstracting services, listed with Open DOAR and Open J-Gate.

Choudhary \& Khode $^{16}$ analysed 114 OA journals in Computer Science included in DOAJ. They concluded that $21 \%$ of the journals are published from USA while only two journals are published from India, and English is the most popular language of the OA Journals in Computer Science. Agashe, Lihitkar \& Lihitkar ${ }^{17}$ analysed 48 Business and Management e-journals listed in the DOAJ and highlighted that USA scored $1^{\text {st }}$ rank by publishing 10 e-journals followed by Brazil. English is the most common communication language used by 41 e-journals. Findings of a study conducted by Sivakumaren ${ }^{18}$, et al., indicated that most of the OA Journals in the field of Library \& Information Science (LIS) 
discipline are published from USA, whereas only 5 OA journals are published from India. English was found the most popular language of communication among LIS OA journals.

\section{RESEARCH OBJECTIVES}

The study aims to identify OA journals in Media \& Communication listed in the DOAJ. The specific objectives of the present study are to:

(i) Know the distribution of open access journals in Media \& Communication

(ii) Identify the overall growth of OA journals

(iii) Identify the leading countries in terms of publishing number of OA journals

(iv) Know the leading publishers of OA journals

(v) Find out the language-wise distribution of $\mathrm{OA}$ journals

(vi) Know the frequency of OA journals

(vii) Identify publishing pattern of OA journals

(viii)Know indexing sources where OA journals are indexed

(ix) Determine the prominent subjects covered by OA journals of Media \& Communication.

\section{METHODOLOGY}

For conducting any research, systematic planning of study is most vital upon which the whole process of research study depends. Such planning acts as a frame of the guidelines while investigating the problem. Since the study was planned to analyse the growth and present status of OA journals in Media \& Communication, survey method was found suitable. To achieve objectives of the present study, data was collected from the most authoritative online directory of open access journals (DOAJ: http://www. doaj.org/). The DOAJ is designed, developed and maintained by Lund University which, as on $15^{\text {th }}$ December 2012, listed 8492 open access journals of which 106 (1.24 \%) journals were listed under the subject heading 'Media and Communication'. The factual data were imported from the website of the DOAJ in Microsoft Excel format for further analysis in terms of number of journals, year and country of origin, language, formats, etc.

\section{RESULTS AND DISCUSSIONS}

\subsection{Year-wise Growth of OA Journals}

The growth in number of OA Journals during last 30 years was analysed. The journals in Media \& Communication are mostly new journals. Based on the existence date in DOAJ, there are 5 journals in 1980s, 10 in 1990s, 76 in 2000s and the remaining 15 have started in 2010s. It is to be noted that, the existence in DOAJ is not necessarily the year of the founding of the journal, as older journals often have back issues that have not yet been digitised and placed online. Table 1 shows the year-wise growth of OA journals in Media \& Communication. It may be observed from the year-wise analysis of open access journals that at the end of 1990s there were a few OA journals in Media \& Communication, but this number rose to 96 at the end of 2009. The $21^{\text {st }}$ century saw a proliferation of OA journals in Media \& Communication.

\subsection{Country-wise Distribution of OA Journals}

Open access journals in Media \& Communication

Table 1. Growth of OA journals

\begin{tabular}{|c|c|c|c|}
\hline Decade & Year & $\begin{array}{l}\text { Number of journals } \\
\text { (Year-wise) }\end{array}$ & $\begin{array}{l}\text { Number of journals } \\
\text { (decade-wise) (\%) }\end{array}$ \\
\hline \multirow{3}{*}{$1980 s$} & 1981 & 2 & \multirow{3}{*}{$5(4.7 \%)$} \\
\hline & 1984 & 1 & \\
\hline & 1985 & 2 & \\
\hline \multirow{5}{*}{$1990 s$} & 1994 & 1 & \multirow{5}{*}{$10(9.5 \%)$} \\
\hline & 1996 & 1 & \\
\hline & 1997 & 2 & \\
\hline & 1998 & 4 & \\
\hline & 1999 & 2 & \\
\hline \multirow{10}{*}{$2000 s$} & 2000 & 5 & \multirow{10}{*}{76 (71.7 \%) } \\
\hline & 2001 & 6 & \\
\hline & 2002 & 4 & \\
\hline & 2003 & 8 & \\
\hline & 2004 & 7 & \\
\hline & 2005 & 11 & \\
\hline & 2006 & 6 & \\
\hline & 2007 & 13 & \\
\hline & 2008 & 13 & \\
\hline & 2009 & 3 & \\
\hline \multirow{3}{*}{$2010 s$} & 2010 & 8 & \multirow{3}{*}{$15(14.1 \%)$} \\
\hline & 2011 & 5 & \\
\hline & 2012 & 2 & \\
\hline Total & & 106 & 106 \\
\hline
\end{tabular}

are published from 34 different countries from 6 continents. South America and North America are the leading continents in OA Journals publishing, while there is only 1 journal published from African continent. As shown in Table 2, highest number of OA journals are published in Brazil (19), followed by the United States (16), Spain (12), Australia and Canada (5). Data presented in the table indicate that 86 journals are published from 14 countries, while remaining 20 journals are published from 20 countries with one journal each. It is important to note that not a single open access journal in Media \& Communication is published from India. However, in LIS, 5 OA journals were being published from 
India as listed in the DOAJ.

\subsection{Leading Publishers of OA Journals}

The vast majority of the OA journals, more Table 2. Country-wise distribution of OA journals

\begin{tabular}{lll}
\hline $\begin{array}{l}\text { S. } \\
\text { No. }\end{array}$ & Countries & $\begin{array}{l}\text { Number of } \\
\text { journals }(\%)\end{array}$ \\
\hline 1. & Brazil & $19(17.9 \%)$ \\
2. & United States & $16(15.9 \%)$ \\
3. & Spain & $12(11.3 \%)$ \\
4. & Australia & $8(7.4 \%)$ \\
5. & Canada & $5(4.7 \%)$ \\
6. & Romania & $5(4.7 \%)$ \\
7. & France & $4(3.7 \%)$ \\
8. & Denmark & $3(2.8 \%)$ \\
9. & Portugal & $3(2.8 \%)$ \\
10. & Sweden & $3(2.8 \%)$ \\
11. & Chile & $2(1.8 \%)$ \\
12. & Finland & $2(1.8 \%)$ \\
13. & Pakistan & $2(1.8 \%)$ \\
14. & Turkey & $2(1.8 \%)$ \\
15. & Other countries who contributed & $20(18.8 \%)$ \\
& only one journal (Argentina, Austria, \\
& Colombia, Croatia, Cyprus, Czech \\
& Republic, Egypt, Germany, Hong & \\
& Kong, Iran, Italy, Lithuania, Malaysia, \\
& Mexico, Netherlands, South Africa, \\
& South Korea, Switzerland, UK, and \\
\hline & Total & \\
\hline
\end{tabular}

than $80 \%$, are published by the not-for-profit sector. Over two-third or 73 journals are published by academic institutions and universities; about $15 \%$ are published by associations and societies (15 journals); and 1 by a library while 17 journals are published by independent publishers and forprofit corporations (Table 3 ). The 106 journals have 99 different publishers; the only seven publishers on the list with 2 journals are: Central Queensland University, Danubius University, University of Texas at Austin, Universidade do Vale do Rio dos Sinos, Universidad Complutense de Madrid, Sammenslutningen af Medieforskere i Danmark, and INTERCOMSociedade Brasileira de Estudos Interdisciplinares da Comunicação.

Table 3. Publisher-wise distribution of OA journals

\begin{tabular}{ll}
\hline Types of publishers & Number of journals (\%) \\
\hline Association/societies & $15(14.2 \%)$ \\
Academic institutions/universities & $73(68.8 \%)$ \\
Library & $1(0.9 \%)$ \\
Independent/commercial publishers & $17(16.1 \%)$ \\
Total & $\mathbf{1 0 6}$ \\
\hline
\end{tabular}

\subsection{Language-wise OA Journals}

English is the most prominent language of publishing OA journals in Media and Communication (Table 4). Out of 106 OA journals, 51 are in English, followed by Portuguese (21), Spanish (16), and French (5), 13 languages are represented in publishing 106 open access journals. Language-wise analysis of $\mathrm{OA}$ journals shows a western-centric list of languages, with only one journal in Persian. This list reflects a greater cultural diversity, but is still lacking in nonwestern representation. Another important finding, as emerged from the analysis, is that out of 106 OA journals of Media \& Communication, 46 are published in two or more languages. Even there is one journal namely 'CIRCULO de Linguistica Aplicada a la Comunicacion' in Spain, which is published in 8 languages (Spanish, English, French, German, Portuguese, Basque, Catalan, and Italian).

\subsection{Frequency of OA Journals}

An attempt was made to identify the frequency of OA Journals in the field of Media and Communication.

Table 4. Language-wise distribution of OA journals

\begin{tabular}{ll}
\hline Language & $\begin{array}{l}\text { Number of } \\
\text { journals }(\%)\end{array}$ \\
\hline English & $51(48.1 \%)$ \\
Portuguese & $21(19.9 \%)$ \\
Spanish & $16(15.1 \%)$ \\
French & $5(4.7 \%)$ \\
German & $3(2.8 \%)$ \\
Catalan & $2(1.8 \%)$ \\
Danish & $2(1.8 \%)$ \\
$\begin{array}{l}\text { Other languages in which only one journal is } \\
\text { published (Turkish, Croatian, Dutch, Romanian, } \\
\text { Lithuanian, Persian) }\end{array}$ & $6(5.8 \%)$ \\
Total & $\mathbf{1 0 6}$ \\
\hline
\end{tabular}

It may be observed from Table 5, that the frequency of 33 journals is twice a year, frequency of 19 journals is thrice a year, frequency of 25 journals is quarterly, frequency of 7 journals is six time a year and the frequency of 11 journals is annually. The

Table 5. Frequency of OA journals

\begin{tabular}{ll}
\hline Frequency & Number of journals (\%) \\
\hline Two times a year & $33(31.2 \%)$ \\
Four times a year & $25(23.6 \%)$ \\
Once a year & $11(10.4 \%)$ \\
Three times a year & $19(17.9 \%)$ \\
Weekly & $3(2.8 \%)$ \\
Monthly & $5(4.7 \%)$ \\
Six times a year & $7(6.6 \%)$ \\
Not fixed & $3(2.8 \%)$ \\
Total & $\mathbf{1 0 6}$ \\
\hline
\end{tabular}


frequency of 3 journals is weekly, whereas issues of 5 journals appeared monthly. The frequency detail of 3 journals could not be traced, and the publication of these journals was irregular.

\subsection{Publishing Pattern of OA Journals}

Table 6 shows that 73 journals are being published online and they do not have their print versions, whereas 33 journals are published online as well as in printed form. When identifying the modes of delivery of the articles of OA journals, it may be observed from Table 7 that 37 journals provide articles in both HTML and PDF format for reading and downloading purposes. Eleven journals provide reading facility in only HTML format, whereas 58 journals present articles in only PDF format.

\subsection{Indexing of OA Journals}

One of the objectives of the present study was to investigate whether OA journals are indexed in

Table 6. Format of OA journals

\begin{tabular}{ll}
\hline Format & Number of journals (\%) \\
\hline Both print and online & $33(31.1 \%)$ \\
Only online & $73(68.9 \%)$ \\
Total & 106 \\
\hline
\end{tabular}

Table 7. Modes of availability of OA journals' articles

\begin{tabular}{ll}
\hline Modes & Number of journals (\%) \\
\hline Only HTML & $11(11.4 \%)$ \\
Only PDF & $58(54.7 \%)$ \\
Both PDF and HTML & $37(34.9 \%)$ \\
Total & 106 \\
\hline
\end{tabular}

indexing and abstracting sources. Indexing and abstracting of journals help in increasing the visibility of their articles; this ultimately contributes to scholarly impact of the journals. When investigating the indexing of the articles/journals, it was observed from the analysis that nearly two-third ( 75 journals out of 106) journals were indexed in one or more indexing and abstracting sources. However, the detail of indexing and abstracting of 22 journals could not be traced out. It is interesting to note that some journals indexed in one indexing or abstracting source, while others indexed up to 10 indexing or abstracting sources. 84 journals of Media and Communication are indexed in 55 different indexing and abstracting sources. It may be observed from Table 8 that out of 84 journals, 75 are indexed in DOAJ, 61 journals are indexed in Ulrich's Periodicals Directory and 57 journals are indexed in EBSCO publishing (Table 8).

\subsection{Subjects Covered by OA Journals}

The subject coverage of the of OA journals
Table 8. Indexing of OA journals

\begin{tabular}{|c|c|}
\hline Name of indexing/abstracting sources & $\begin{array}{l}\text { No. of journal } \\
\text { indexed }\end{array}$ \\
\hline Directory of Open Access Journals & 75 \\
\hline Ulrich's Periodicals Directory & 61 \\
\hline EBSCO Publishing & 57 \\
\hline Index Copernicus & 36 \\
\hline Sociological Abstracts & 34 \\
\hline Social Science Research Network & 29 \\
\hline Open J Gate & 27 \\
\hline J-Gate & 24 \\
\hline Columbia International Affairs Online & 21 \\
\hline Academic Journal Database & 21 \\
\hline EBSCO database of electronic Journals & 20 \\
\hline Scopus & 17 \\
\hline $\begin{array}{l}\text { Current Contents of Periodicals on the Middle } \\
\text { East }\end{array}$ & 17 \\
\hline Academic Search Premier & 16 \\
\hline EBSCO Host & 16 \\
\hline Global Development Network & 15 \\
\hline Genamics JournalSeek & 15 \\
\hline JournalSeek Genomics & 15 \\
\hline $\begin{array}{l}\text { International Consortium for the Advancement } \\
\text { of Academic Publications }\end{array}$ & 15 \\
\hline $\begin{array}{l}\text { International Bibliography of the Social } \\
\text { Sciences }\end{array}$ & 15 \\
\hline New Jour Databases & 14 \\
\hline MediaFinder® & 14 \\
\hline ProQuest Research Library & 13 \\
\hline Proquest & 13 \\
\hline Scirus & 12 \\
\hline World Cat & 11 \\
\hline Social Services Abstracts & 11 \\
\hline Bielefeld Academic Search Engine & 9 \\
\hline Caboose Open Directory & 8 \\
\hline Cabell Directory of Publishing Opportunities & 8 \\
\hline CiteseerX & 7 \\
\hline Central and Eastern European Online Library & 7 \\
\hline GALE Academic OneFile & 6 \\
\hline European Sources Online & 6 \\
\hline Eurolnternet & 6 \\
\hline ERIC & 6 \\
\hline Electronic Journals Library & 6 \\
\hline Gale Expanded Academic Index & 5 \\
\hline HW Wilson's Social Sciences Index & 4 \\
\hline SafetyLit & 3 \\
\hline Norwegian Social Science Data Services & 3 \\
\hline Knowledge Base Eastern Europe & 3 \\
\hline SwetsWise & 2 \\
\hline Standard Periodical Directory & 2 \\
\hline Scipio & 2 \\
\hline
\end{tabular}




\begin{tabular}{ll}
\hline Name of indexing/abstracting sources & $\begin{array}{l}\text { No. of journal } \\
\text { indexed }\end{array}$ \\
\hline International Relations and Security Network & 2 \\
Social Science Citation Index & 1 \\
Socionet & 1 \\
SciELO Colombia & 1 \\
GeoDados & 1 \\
Compendex & 1 \\
Central and Eastern European Online Library & 1 \\
Cabell & 1 \\
Total & 736 \\
\hline
\end{tabular}

Note: Total journals exceeds from 84 (in which indexing detail was given) because some journals are indexed in more than one indexing and abstracting sources.

Table 9. Subject coverage of OA journals

\begin{tabular}{|c|c|}
\hline Subjects & $\begin{array}{l}\text { No. of } \\
\text { journals }\end{array}$ \\
\hline Communication & 20 \\
\hline Journalism & 19 \\
\hline Media communication & 17 \\
\hline Theory of electronic media & 16 \\
\hline Information and communication technologies & 11 \\
\hline Social communication & 11 \\
\hline Communication studies & 9 \\
\hline Scientific communication & 8 \\
\hline Intercultural research & 7 \\
\hline Media studies & 5 \\
\hline Information science & 3 \\
\hline International communication & 3 \\
\hline Mass media & 3 \\
\hline Visual culture & 3 \\
\hline Journalism theory & 2 \\
\hline Media theory & 2 \\
\hline Multimedia programming application & 2 \\
\hline Press studies & 2 \\
\hline Public relations & 2 \\
\hline Communication methods & 1 \\
\hline Communication research & 1 \\
\hline Communication science & 1 \\
\hline Communication theory & 1 \\
\hline Communications technology & 1 \\
\hline Global culture & 1 \\
\hline Human science & 1 \\
\hline Intercultural research & 1 \\
\hline Interdisciplinary studies & 1 \\
\hline Mass communication & 1 \\
\hline Urban culture & 1 \\
\hline
\end{tabular}

in Media \& Communication is quite interesting. Table 9 shows that OA journals of Media and Communication cover 30 subjects. 'Communication' is the most prominent subject, which is covered by $19 \%$ OA journals, followed by Journalism (18 $\%)$, Media communication (16\%) and Theory of electronic media (15\%).

\section{CONCLUSIONS}

The OA journals are now clearly and broadly being recognised as essential vehicle for scholarship in the digital world. This is evident based on the continuous growth of OA journals in different disciplines around the world. The OA journals in Media and Communication were mostly new journals started during late 1990s and published in 34 different countries of 6 continents, where Brazil tops the rank, followed by USA, Spain, Australia and Canada. It is surprising to note that India's contribution towards OA journals in Media \& Communication is almost nil. At present, most of the OA journals in Media \& Communication are published from academic institutions particularly universities. So, it is now time for Indian universities to take initiatives in publishing $O A$ journals. At the same time researchers, lecturers, and practitioners within institutions need to convince the value and immense potential of OA journals. The continued development of OA journals depends a great deal on our continuing to overcome cultural, legal and financial barriers to their acceptance and use. Most of the public funding research institutions in India have started providing free access to their journals over the internet. It may be expected that in the next few years we will see sustainable growth of OA Journals as some leading publishers are also taking interest in OA journals publishing.

\section{REFERENCES}

1. Wikipedia. Scholarly communication. http:// en.wikipedia.org/wiki/Scholarly_communication/ (accessed on 15 December 2012).

2. UC Davis University Library. http://www.lib. ucdavis.edu/ul/about/schcomm/ (accessed on 15 December 2012).

3. Harnad, S. The self-archiving initiative. Nature: Web debates, 2002. http://www.nature.com/ nature/debates/e-access/Articles/harnad.html/ (accessed on 15 December 2012).

4. Association of Research Libraries. New paradigms: The OA movement, 2005. http://www.arl.org/sc/ models/oa.shtml/ (accessed on 15 December 2012).

5. Ali, A. Ane's Encyclopedic Dictionary of Library \& Information Science. Ane Book, New Delhi, 2005.

6. Prosser, D. Institutional repositories and open access: The future of scholarly communication. Inf. Serv. \& Use, 2003, 23, 167-70.

7. Anbu K.J.P. Towards a vertical portal for open access scholarly publications. Information Studies, 2006, 12(1), 27-34. 
8. Ratnakar, A. Open access journals: A myth or reality. Library Herald, 2007, 45(1), 12-19.

9. Nazim, M. \& Maya Devi. Open access journals and institutional repositories: Practical need and present trends in India. Annals Lib. Inf. Stud., 2008, 55(1), 201-08.

10. Keisham, S. \& Soubam S. Open access journals and initiatives in India. In Proceedings of $6^{\text {th }}$ Convention PLANNER, INFLIBNET Centre, Ahmedabad, 2008.

11. Arunachalam, S. Open access in India: Hopes and frustrations. In Open Scholarship: Authority, Community, and Sustainability in the Age of Web 2.0, edited by Leslie Chan \& Susanna Mornati. Proceedings of the $12^{\text {th }}$ International Conference on Electronic Publishing, 25-27 June 2008, Toronto, Canada. pp. 271-79. http://elpub. scix.net/scgi-bin/works/Show?271_elpub2008/ (accessed on 15 December 2012).

12. Kumar, A. Open access to research literature in India: Contemporary scenario. ISSI Newsletter, 2009, 5(1), 9-14. http:/s/www.issi-society.info/ newsletter.html/ (accessed on 15 December 2012).

13. Lone, F.; Rafiq R. \& Shah, G.J. Indian contribution to open access literature: A case study of DOAJ \& Open DOAR. Chinese Lib.: An Int. Electr. J., 2008, 26, 1-10. http://www.iclcs.us/cliej/c126fayaz. $\mathrm{htm} /$ (accessed on 15 December 2012).

14. Bhat, M.H. Open access publishing in Indian premier research institutions. Information Research, 2009, 14(3). http://information r.net/ir/14-3/paper409. html/ (accessed on 15 December 2012).

15. Sawant, S. The current scenario of open access journals initiatives in India. Collection Building, 2009, 28(4), 159.

16. Choudary, A. \& Khode S. Analysis of open access journals in the area of computer science. SRELS J. Inf. Manag., 2010, 47(3), 339-44.

17. Agashe, A.T.; Lihitkar, S.R. \& Lihitkar, R.S. Free online journals on business and management in directory of open access journals (DOAJ).
SRELS J. Inf. Manag., 2010, 47(1), 41-58.

18. Sivakumaren, K.S., et al. A study on open access journals in library and information science: With reference to DOAJ. Int. J. Lib. Sci., 2012, 6(2).

\section{About the Authors}

Professor Shabahat Husain is working as Dean, Faculty of Arts and Head, Department of Library \& Information Science (LIS), Aligarh Muslim University, Aligarh. He has more than 35 years of experience in teaching and library administration, and is member of various national level committees of UGC. He holds a PhD in LIS from Lucknow University, and MPhil in Information Technology from Loughborough University of Technology, England. Prior to his current assignments he has served Maulana Azad Library (Central Library of Aligarh Muslim University) as University Librarian during 2008-2012. He has also worked as Lecturer, in the Department of LIS, University of Maiduguri, Nigeria during 19801983. His areas of specialisation are: Information retrieval techniques, information technology, design of front-end systems, library classification and library management.

Dr Mohammad Nazim is working as Assistant Librarian in Faculty of Law, Banaras Hindu University, Varanasi. He received BLIS and MLIS from Aligarh Muslim University, Aligarh and PhD in LIS from Banaras Hindu University, Varanasi. He is recipient of best paper awards for presenting papers in conferences of Indian Library Association and Society for Information Science. He has contributed 25 research articles in various highly reputed national and international journals. His areas of specialisation are: E-learning, open access to scholarly communication, and knowledge management. 